\title{
Chapter 7 \\ Reframing Educational Leadership \\ Research in the Twenty-First Century
}

\author{
David NG
}

\subsection{Introduction}

Educational leadership research has come of age. From its fledgling start in 1960s under the overarching research agenda of educational administration for school improvement, the focus shifted to leadership research from the early 1990s (Boyan, 1981; Day et al., 2010; Griffiths, 1959, 1979; Gronn, 2002; MacBeath \& Cheng, 2008; Mulford \& Silins, 2003; Southworth, 2002; Witziers, Bosker, \& Kruger, 2003). Since then, educational leadership as a respected field began to flourish by the early 2000s (Hallinger, 2013; Robinson, Lloyd, \& Rowe, 2008; Walker \& Dimmock, 2000). From the 1980s up to the present time, the body of knowledge on educational leadership has grown tremendously to produce three distinctive educational leadership theories: Instructional leadership, transformational leadership, and distributed leadership. While it is undisputed that educational leadership research has indeed been productive, there is a sense that a narrowing labyrinth of researchable questions is approaching in particular to the first two educational leadership research theories. The evidence of this is implied in the concerted call to expand and situate educational leadership research in non-Western societies (Dimmock, 2000; Dimmock \& Walker, 2005; Hallinger, 2011; Hallinger, Walker, \& Bajunid, 2005). This call is valid in that there is still limited contribution to substantive theory building from non-Western societies. However, it also implies that Western societies' focus on educational leadership has reached an optimum stage in publications and knowledge building. A more pertinent reason to rethink educational leadership research could be based on epistemological questions about the social science research paradigm that has been the foundation of educational leadership research.

D. NG $(\bowtie)$

National Institute of Education, Nanyang Technological University, Singapore, Singapore

e-mail: david.ng@nie.edu.sg

A. Oude Groote Beverborg et al. (eds.), Concept and Design Developments in School Improvement Research, Accountability and Educational Improvement, https://doi.org/10.1007/978-3-030-69345-9_7 
These questions will be expanded as the discussion proceeds on current approaches of educational leadership research.

This chapter has three goals: The first one is to map the data-analytical methods used in educational leadership research over the last thirty years (1980-2016). This investigation covers the research methodologies used in instructional leadership, transformational leadership, and distributed leadership.

Educational leadership studies are conducted in the social context of the school. This context involves complex social interactions between and among leaders, staff, parents, communities, partners, and students. In the last decade, there has been a consensus among scholars that schools have evolved to become more complex. Furthermore, there is a consensus among scholars to view complexity through increases in the number of actors and the interactions between them. The complexity of schools is evident in the rise in accountability and involvement from an expanding number of stakeholders involved, such as politicians, clinical professionals (who diagnose learning disabilities of students), communities, and educational resource providers (training and certifying institutions). The relations between stakeholders are non-linear and discontinuous, so even small changes in variables can have a significant impact on the whole system. Therefore, the second goal is to determine whether methodologies that are adequate for the assessment of complex interaction patterns, influences, interdependencies, and behavioural outcomes that are associated with the social context of the school, have been adopted over the past three decades.

The third goal is to explore potential methodologies in the study of educational leadership. These alternative methodologies are taken from more recent developments of research methodologies used in other fields. These fields, such as health, development of society, among others, have similarities with the study of educational leadership. The common link is the social contexts and the system's influence involving the spectrum of interactions, change, and emergence. We will examine published empirical research and associated theories that look at influence, interdependencies, change, and emergence. Adopting these alternative methodologies will enable reframing educational leadership so it can move forward. Three questions guide the presentation of this paper:

- What are the data sources and analytical methods adopted in educational leadership research?

- What is the current landscape of schooling and how does it challenge current educational leadership research methodologies?

- What are some possible alternative research methodologies and how can they complement current methodologies in educational leadership research?

This chapter proposes to reframe educational leadership studies in view of new knowledge and understanding of alternative research data and analytical methods. It is not the intent of the paper to suggest that current research methodologies are no longer valid. On the contrary, the corpus knowledge of current social science research methodologies practiced, taught, and learned through the past three decades cannot be dismissed lightly. Instead of proposing to reframe educational leadership 
studies, the main purpose of this paper is to explore and propose complementary research methodologies that will open up greater opportunities for research investigation. These opportunities are linked to the functions of adopting alternate analytical research tools.

\subsection{What Are the Dominant Methodologies Adopted in Educational Leadership Research?}

Educational leadership research adopts a spectrum of methods that conform to the characteristics of disciplined inquiry. Cronbach and Suppes (1969) defined disciplined inquiry as "conducted and reported in such a way that the argument can be painstakingly examined" (p. 15). What this means is that any data collected and interpreted through reasoning and arguments must be capable of withstanding careful scrutiny by another research member in the field.

This section looks at the disciplined inquiry methods adopted and implemented in the last thirty years that have contributed to the current body of knowledge on educational leadership and management. The pragmatic rationale to impose a time frame for the review is that instructional leadership was conceptualized in the 1980s, followed by transformational leadership and in recent years, distributed leadership. The purpose of this review is to identify, if possible, all quantitative and qualitative methods adopted. The next section provides a broad overview of the three educational leadership theories/models. This will anchor the discussion on alternate research methodologies that will reframe and expand the research on these theories/models.

\subsubsection{Instructional, Transformational, and Distributed Leadership}

Instructional leadership became popular during the early 1980s. There are two general concepts of instructional leadership - one is narrow while the other is broad (Sheppard, 1996). The narrow concept defines instructional leadership as actions that are directly related to teaching and learning, such as conducting classroom observations. This was the earlier conceptualization of instructional leadership in the 1980s, and it was normally applied within the context of small, poor urban primary schools (Hallinger, 2003; Meyer \& Macmillan, 2001). The broad concept of instructional leadership includes all leadership activities that indirectly affect student learning, including school culture, and time-tabling procedures by impacting the quality of curriculum and instruction delivered to students. This conceptualization acknowledges that principals, as instructional leaders, have a positive impact on students' learning, but that this influence is mediated (Goldring \& Greenfield, 2002; 
Leithwood \& Jantzi, 2000; Southworth, 2002). A comprehensive model of instructional leadership was developed by Hallinger and Murphy $(1985,1986)$. This dominant model proposes three dimensions of the instructional leadership construct: defining the school's mission, managing the instructional program, and promoting a positive school-learning climate. Hallinger and Heck (1996), in their comprehensive review of research on school leadership, concluded that instructional leadership was the most commonly researched. The authors' focused review found that over 125 empirical studies employed this construct between 1980 and 2000 (Hallinger, 2003). In the last decade, instructional leadership has regained prominence and attention in part because of the lack of empirical studies in non-Western societies. This can also be inferred from the notion that leadership in curriculum and instruction still matters and remains the core business of schools.

Transformational leadership was introduced as a theory in the general leadership literature during the 1970s and 1980s (e.g. Bass, 1997; Howell \& Avolio, 1993). Transformational leadership focuses on developing the organisation's capacity and commitment to innovate (Leithwood \& Duke, 1999). Correspondingly, transformational leadership is supposed to enable change to occur (Leithwood, Tomlinson, \& Genge, 1996). Amongst the leadership models, transformational leadership is the one most explicitly linked to the implementation of change. It quickly gained popularity among educational leadership researchers during the 1990s in part because of reports of underperforming schools as a result of top-down policy driven changes in the 1980s. Sustained interest during the 1990s was also fuelled by the perception that the instructional leadership model is a directive model (Hallinger \& Heck, 1996). In a pointed statement of the extent of instructional leadership research, Hallinger (2003, p. 343) emphatically notes that "The days of the lone instructional leader are over. We no longer believe that one administrator can serve as the instructional leader for the entire school without the substantial participation of other educators." From the beginning of the 2000s, a series of review studies comparing the effects of transformational leadership and instructional leadership, the "overprescriptivity' of findings, the limited methodologies adopted, and a lack of international research contributed to the waning interest in transformational leadership (Robinson et al., 2008, Robinson, 2010).

Interest in distributed leadership took off at around 2000. Gronn (2002), and Spillane, Halverson, and Diamond (2004) are leading the current debate on distributed leadership as observed by Harris (2005). Gronn's concept of distributed leadership is a "purely theoretical exploration" (p. 258) while Spillane's and his various colleagues' work is based on empirical studies that are still ongoing. When Gronn and Spillane first proposed their concepts of distributed leadership, what was revolutionary was a shift from focusing on the leadership actions of an individual as a sole agent to analyzing the 'concertive' or 'conjoint' actions of multiple individuals interacting and leading within a specific social and cultural context (Bennett, Wise, Woods, \& Harvey, 2003; Gronn, 2002, 2009; Spillane, 2005; Woods, 2004). In addition, Spillane, Diamond, and Jita (2003) explicitly relate their concept of distributed leadership to instructional improvement, which, therefore, catalyzes the interest among researchers to explore the constructs in school improvement and 
effectiveness. From 2000 to 2016, a focused search for empirical studies that employed the constructs of distributed leadership yielded over 97 studies.

\subsubsection{Assessment of the Dominant Methodologies in Educational Leadership Research and Courses}

The purpose of this review is to identify, if possible, all the quantitative and qualitative methods adopted. This review is based on a combined search for the three educational leadership theories in schools using the following search parameters:

- Keywords in database search: "instructional leadership" OR "transformational leadership" OR "distributed leadership"

- Limiters: Full Text; Scholarly (Peer-reviewed) Journals; Published Date: 1980-2016

- Narrow by Methodology: quantitative study

- Narrow by Methodology: qualitative study

- Search modes: Find all search terms

- Interface: EBSCOhost Research Databases

- Database: Academic Search Premier; British Education Index; Education Source; ERIC

The search yielded over 672 empirical studies employing the constructs of instructional leadership, transformational leadership, and distributed leadership. As the purpose of the review is to identify all quantitative and qualitative methods adopted, only that information was extracted. The researchers carefully read the relevant sections of the 672 studies pertaining to methodologies and extracted that information. An overview of the results is given in Tables 7.1 and 7.2.

The range of quantitative and qualitative research methodologies and analytical tools found in the review was categorized as follows:

Quantitative Analyses:

- Univariate Analysis:

- The analysis refers to a single variable represented by frequency distribution, mean and standard deviation.

- Bivariate Analysis:

- This type of analysis examines how two variables are related to each other, represented by ANOVA, Pearson product moment correlations, correlation and regression.

- Multivariate Analysis:

- These are statistical procedures that are used to reach conclusions about associations between two or more variables. Representations of inferential statistics include regression coefficients, MANOVA, MANCOVA, two-group comparison (t-test), factor analysis, path analysis, hierarchical linear modelling, and others. 
Table 7.1 Quantitative methods used in the study of instructional, transformational, and distributed leadership

\begin{tabular}{|c|c|c|}
\hline Data source: & Types: & Specific analytical methods: \\
\hline \multirow[t]{26}{*}{ Questionnaire/survey } & \multirow[t]{5}{*}{ Basic statistics } & Frequency distribution \\
\hline & & Mean \\
\hline & & Median \\
\hline & & Standard deviation \\
\hline & & t-test \\
\hline & \multirow[t]{4}{*}{ Analysis of variance } & Analysis of covariance \\
\hline & & Analysis of variance \\
\hline & & One-way ANOVA \\
\hline & & Two-way ANOVA \\
\hline & \multirow[t]{2}{*}{ Association and correlation } & Correlation \\
\hline & & Regression \\
\hline & \multirow[t]{4}{*}{ Causal modelling } & Dependent variable \\
\hline & & Independent variable \\
\hline & & Path analysis \\
\hline & & Structural equation modelling \\
\hline & \multirow[t]{5}{*}{ Factor analysis } & Exploratory factor analysis \\
\hline & & Factor analysis \\
\hline & & Confirmatory factor analysis \\
\hline & & Oblique rotation \\
\hline & & Rotated factor \\
\hline & \multirow[t]{3}{*}{ Linear and multilevel analysis } & Generalized linear model \\
\hline & & Hierarchical generalized linear model \\
\hline & & Hierarchical linear modelling \\
\hline & \multirow[t]{3}{*}{ Multilevel regression } & Multicollinearity \\
\hline & & Multiple regression analysis \\
\hline & & Interaction effect \\
\hline
\end{tabular}

Data source: Questionnaire/Survey

Qualitative Analyses:

- Content Analysis:

- Content analysis is the systematic analysis of the text by adopting rules that can separate the text into units of analysis, such as assumptions, effects, enablers and barriers. The text is obtained through document search, artifacts, interviews, field notes, or observations. The transcribed data are converted into protocols followed by categories. Coding schemes are then applied to determine themes and their relations.

- Hermeneutic Analysis:

- With this type of analysis, researchers interpret the subjective meaning of a given text within its socio-historic context. Methods adopted extend beyond texts to encompass all forms of communication, verbal and non-verbal. An iterative analyses method between interpretation of text and holistic under- 
Table 7.2 Qualitative methods used in the study of instructional, transformational, and distributed leadership

Data sources:

One-to-one interview

Focus group interview

Document search (e.g. writing samples, e-mail correspondence, and district literature)

Field notes

Classroom observations

Semi-structured interviews

Artifacts

Shadowing

Interview protocols (for multiple case studies)

Interpretive description

Topic-oriented

The voices from the field

Cross-cultural comparative studies

Portfolios

Micro-political analysis

Specific analytical methods:

Thematic analysis ("coding" and then segregating the data by codes into data clumps for further analysis and description)

Discrepancy theme

Characteristics

Descriptive

Factors

Roles

Nature

Content analysis

Causal sequence

Interactions but also in social, cultural, and institutional discourses

Structured coding scheme derived from the conceptual framework

Exploratory analysis

Phenomenology and constant comparative methods

Comparative analysis: Finding common themes, and contrasts

Detailed analytical memo

Vertical analysis: Analyzing participants' voices separately; and patterns and elucidating the differences among participants' voices.

standing of the context is adopted in order to develop a fuller understanding of the phenomenon.

- Grounded-theory Analysis:

- This is an inductive technique of interpreting recorded data about a social phenomenon. Data acquired through participant observation, in-depth interviews, focus groups, narratives of audio/video recordings, and documents are interpreted based on empirical data. A systematic coding technique 
involving open coding, axial coding, and selective coding is rigorously applied. These coding techniques aim to identify key ideas, categories, and causal relations among categories, finally arriving at a theoretical saturation where additional data and analyses do not yield any marginal change within the core categories.

On the one hand, these results show that a wide range of both quantitative and qualitative methodologies are applied and that the field is open to a lot of diversity in methodologies, but, on the other hand, the results also show that complexity methodology is missing completely.

One of the purposes of this paper is to identify current research methodologies that have been adopted for the past decades. The following review is to ascertain whether current research methodologies adopted are also reinforced and transmitted by the research courses offered by top universities. A search was conducted that specifically looked at graduate research courses taught in educational leadership and management. The following search parameters were used:

- Identify the top 20 universities that offer graduate courses in educational leadership and management.

- QS ranking of universities is chosen over Times ranking because QS ranking is sorted by subject: Education and searchable by educational leadership.

- Representation of Western and Eastern universities in order to provide a representation of universities globally.

The findings are presented in Table 7.3. This table is remarkably similar to Tables 7.1 and 7.2 but with more details of the topics in educational leadership research methodologies. The previously presented findings of the methodologies used in educational leadership research strongly suggest that the research methodologies currently adopted in educational leadership studies are reinforced by research courses taught at the top universities. Indeed, the transmission and application of research skills is a critical and essential component of graduate programmes. This transmission of knowledge and practice is strengthened by the enshrined supervisorsupervisee relationship where cognitive modelling takes place through discourse, reflection, guidance, and inquiry. The one-to-one supervision has the very powerful effect of instilling expectations, cultivating habits, and shaping practices that contribute to a competent researcher identity. It is noteworthy that the transmissionbased form has emanated from and is continued in the paradigm of social science. Table 7.3 presents the research courses that are currently taught at the top 20 universities offering educational leadership research. 
Table 7.3 Research courses in Educational Leadership taught at the Top 20 universities

\begin{tabular}{|c|c|c|}
\hline Quantitative courses: & Qualitative courses: & Universities: \\
\hline $\begin{array}{l}\text { Basic descriptive measures summarizing data using } \\
\text { statistics, such as frequency, mean, and variance; }\end{array}$ & Content analysis & $\begin{array}{l}\text { The UCL Institute } \\
\text { of Education }\end{array}$ \\
\hline Random sampling and sampling error & Ethnography & $\begin{array}{l}\text { Harvard } \\
\text { University }\end{array}$ \\
\hline Hypothesis tests for continuous and categorical data & Critical ethnography & $\begin{array}{l}\text { Stanford } \\
\text { University }\end{array}$ \\
\hline $\begin{array}{l}\text { Modelling continuous data using simple linear } \\
\text { regression }\end{array}$ & $\begin{array}{l}\text { Pragmatic qualitative } \\
\text { research }\end{array}$ & $\begin{array}{l}\text { University of } \\
\text { Cambridge }\end{array}$ \\
\hline $\begin{array}{l}\text { General linear model: Regression, correlation, } \\
\text { analysis of variance, and analysis of covariance }\end{array}$ & $\begin{array}{l}\text { Phenomenological } \\
\text { analysis }\end{array}$ & $\begin{array}{l}\text { The University of } \\
\text { Melbourne }\end{array}$ \\
\hline $\begin{array}{l}\text { Multiple linear regression, including categorical } \\
\text { covariates and interaction effects, factorial ANOVA, } \\
\text { ANCOVA, MANOVA, MANCOVA, partial and } \\
\text { semi-partial correlations, path analysis, exploratory } \\
\text { factor analysis, and confirmatory factor analysis. }\end{array}$ & Discourse analysis & $\begin{array}{l}\text { The University of } \\
\text { Hong Kong }\end{array}$ \\
\hline $\begin{array}{l}\text { Basic statistical inference, including confidence } \\
\text { intervals and hypothesis testing; multiple linear } \\
\text { regression, including categorical variables and } \\
\text { interaction effects }\end{array}$ & $\begin{array}{l}\text { Analysis of visual } \\
\text { materials }\end{array}$ & $\begin{array}{l}\text { University of } \\
\text { Oxford }\end{array}$ \\
\hline Structural equation modelling & $\begin{array}{l}\text { Policy documentary } \\
\text { analysis }\end{array}$ & $\begin{array}{l}\text { University of } \\
\text { California, LA } \\
\text { (UCLA) }\end{array}$ \\
\hline SEM with observed variables & $\begin{array}{l}\text { Historical } \\
\text { documentary } \\
\text { analysis }\end{array}$ & $\begin{array}{l}\text { The University of } \\
\text { Sydney }\end{array}$ \\
\hline SEM with latent variables & $\begin{array}{l}\text { Classroom } \\
\text { ethnography }\end{array}$ & $\begin{array}{l}\text { Nanyang } \\
\text { Technological } \\
\text { University }\end{array}$ \\
\hline $\begin{array}{l}\text { Maximum likelihood estimating, goodness-of-fit } \\
\text { measures, nested models }\end{array}$ & Survey & $\begin{array}{l}\text { University of } \\
\text { California, } \\
\text { Berkeley (UCB) }\end{array}$ \\
\hline Binary and multinomial logistic models & Grounded theory & $\begin{array}{l}\text { Columbia } \\
\text { University }\end{array}$ \\
\hline
\end{tabular}


Table 7.3 (continued)

\begin{tabular}{|c|c|c|}
\hline Quantitative courses: & Qualitative courses: & Universities: \\
\hline \multirow[t]{14}{*}{ Instrument reliability and validity } & Action research & $\begin{array}{l}\text { University of } \\
\text { Michigan }\end{array}$ \\
\hline & $\begin{array}{l}\text { Participatory } \\
\text { research }\end{array}$ & $\begin{array}{l}\text { University of } \\
\text { Wisconsin- } \\
\text { Madison }\end{array}$ \\
\hline & $\begin{array}{l}\text { Bibliographic } \\
\text { analysis }\end{array}$ & $\begin{array}{l}\text { The Hong Kong } \\
\text { Institute of } \\
\text { Education }\end{array}$ \\
\hline & $\begin{array}{l}\text { Institutional } \\
\text { ethnography }\end{array}$ & $\begin{array}{l}\text { Monash } \\
\text { University }\end{array}$ \\
\hline & Narrative & $\begin{array}{l}\text { University of } \\
\text { Toronto }\end{array}$ \\
\hline & $\begin{array}{l}\text { Observation and } \\
\text { interview }\end{array}$ & $\begin{array}{l}\text { University of } \\
\text { British Columbia }\end{array}$ \\
\hline & Interviews & $\begin{array}{l}\text { Michigan State } \\
\text { University }\end{array}$ \\
\hline & Oral history & \multirow{7}{*}{$\begin{array}{l}\text { The Chinese } \\
\text { University of } \\
\text { Hong Kong }\end{array}$} \\
\hline & Arts-based research & \\
\hline & $\begin{array}{l}\text { Critical transnational } \\
\text { ethnography }\end{array}$ & \\
\hline & Hermeneutics & \\
\hline & Phenomenology & \\
\hline & Semiotics & \\
\hline & Crystallization & \\
\hline
\end{tabular}

\subsection{Limitations of the Dominant Methodologies in Educational Leadership Research and Courses}

The range of methodologies and analytical tools reviewed above are disciplined inquiry methods in social science. Social sciences are the science of people or collections of people, such as groups, firms, societies, or economies, and their individual or collective behaviours; social sciences can be classified into different disciplines, such as psychology (the science of human behaviours), sociology (the science of social groups), and economics (the science of firms, markets, and economies). This section is not intended to wade into epistemological and ontological debates within the social sciences. It is also not possible to have an in-depth discussion on social science methodologies within the constraints of this paper. To highlight ongoing discussions about limitations of social science research is the focus of this paper.

Educational leadership is not a discipline by itself, but a field of study that involves events, factors, phenomena, organizations, topics, issues, people, and processes related to leadership in educational settings. This field of study adopts social science inquiry methods. The review of research methodologies, as depicted in 
Tables 7.1 and 7.2, strongly suggests that educational leadership research subscribed to the functionalist paradigm (Bhattacherjee, 2012). The functionalist paradigm suggests that social order or patterns can be understood in terms of their functional components. Therefore, the logical steps will involve breaking down a problem into small components and studying one or more components in detail using objectivist techniques, such as surveys and experimental research. It also encompasses an indepth investigation of the phenomenon in order to uncover themes, categories, and sub-categories.

Educational leadership studies, using quantitative methods, aim to minimize subjectivity. Hence, the constant advocacy of good sampling techniques and a large sample size in order to represent a population where the sample is reported by mean, standard deviation, and normal distribution, among others. Qualitative methods rest upon the assumption that there is no single reality for events, phenomena, and meaning in the social world. Adopting a disciplined analytical method based on dense contextualized data in order to arrive at an acceptable interpretation of complex social phenomena is advocated. The following section will discuss several common limitations of social science research.

\subsubsection{Population, Sampling, and Normal Distributions}

Based on the review, quantitative and qualitative methods of social science in educational leadership research can be inferred to subscribe to the goals of identifying and analyzing data that can inform about a population. Researchers aim to collect data that either maximize generalization to the population in the case of quantitative methods or provide explanation and interpretation of a phenomenon that represents a population in the case of qualitative methods. In most cases, definitive conclusions of a population are rarely possible in social sciences because data collection of an entire population is seldom achieved.

Therefore, researchers apply sampling procedures where the mean of the sampling distribution will approximate the mean of the true population distribution, which has come to be known as normal distribution. This concept has set the parameters as to how data has been collected and analyzed over many years. It has become widely accepted that most data ought to be near an average value, with a small number of values that are smaller, and the other extreme where values are larger. To calculate these values, the probability density function (PDF), or density of a continuous random variable, is used. It is a function that describes the relative likelihood for this random variable to take on a given value.

A simple example will help to explain this: If 20 school principals were randomly selected and arranged within a room according to their heights, one would most likely see a normal distribution: with a few principals who are the shortest on the left, the majority in the middle, and a few principals who are the tallest on the right. This has come to be known as the normal curve or probability density function. 
Most quantitative research involves the use of statistical methods presuming independence among data points and Gaussian "normal" distributions (Andriani \& McKelvey, 2007). The Gaussian distribution is characterized by its stable mean and finite variance (Torres-Carrasquillo et al., 2002). Suppose that in the example above the shortest principal is $1.6 \mathrm{~m}$. Given the question, "What is the probability of a principal in the line being shorter than $1.5 \mathrm{~m}$ ?", the answer would be '0'. From the total number of principals in the room, there is no probability to find someone who is shorter than $1.6 \mathrm{~m}$. But if the question were, "What is the probability of a principal in the line being $1.7 \mathrm{~m}$ ?", then the answer could be 0.2 (i.e. $10 \%$, or 2 persons). Hence, this explains the finite variance, which is dependent upon the sample size. Normal distributions assume few values far from the mean and, therefore, the mean is representative of the population. Even largest deviations, which are exceptionally rare, are still only about a factor of two from the mean in either direction and are well-characterized by quoting a simple standard deviation (Clauset, Shalizi, \& Newman, 2009). This property of the normal curve, in particular the notion that extreme ends of variance are less likely to occur, has significant implications as will be discussed.

Is the normal distribution the standard to determine acceptable findings in educational research? One possible answer is a study done by Micceri (1989). His investigation involved obtaining secondary data from 46 different test sources and 89 different populations, and that included psychometric and achievement/ability measures. He managed to obtain analyzed data from 440 researchers; he then submitted these secondary data to analysis and found that they were significantly non-normal at the alpha .01 significance level. In fact, his findings showed that tail weights, exponential-level asymmetry, severe digit preferences, multi-modalities, and modes external to the mean/median interval were evident. His conclusion was that the underlying tenets of normality-assuming statistics appear fallacious for the psychometric measures. Micceri (1989, p. 16) added that "one must conclude that the robustness literature is at best indicative."

In another well-cited article in the Review of Educational Research, Walberg, Strykowski, Rovai, and Hung (1984, p. 87) state that "considerable evidence shows that positive-skew distributions characterize many objects and fundamental processes in biology, crime, economics, demography, geography, industry, information and library sciences, linguistics, psychology, sociology, and the production and utilization of knowledge." Perhaps the most pointed statement made by Walberg et al., that "commonly reported univariate statistics such as means, standard deviations, and ranges - as well as bivariate and multivariate statistics [...] and regression weights - are generally useless in revealing skewness" is worthy to note.

What are the implications and limitations of the normal distribution in the population? There are at least two limitations. First, reliance on normal distribution statistics puts a heavy burden on assumptions and procedures. The procedures of randomness and equilibrium have powerful influences on how theories are built and also determine how research questions are formulated. In other words, findings may be rejected that could otherwise be informative because they do not meet the normal distribution litmus. The explanation of the normal distribution suggests that any 
events or phenomena at both (extreme) ends of the normal curve are highly unlikely - consequently, we typically reject those findings. Research on real-world phenomena, e.g. social networks, banking networks, and world-wide web networks, has established that events in the tails are more likely to happen than under the assumption of a normal distribution (Mitzenmacher, 2004). Many real-world networks (world-wide web, social networks, professional networks, etc.) have what is known as long-tailed distribution instead of normal distribution.

Second, independent variables contributing to a normal distribution assume that the variables are static. The reality is that in education (and educational leadership) the variables are dynamic. This dynamic function comes from past and even future environmental and individual influences. An example is that of being fortunate to have initial advantages, such as enrolling in a university study (past influence), working with eminent researchers (preferential attachment), obtaining well-funded research projects, and having publication opportunities (environmental influence), combine multiplicatively over time and accumulate to produce a highly skewed number of publications. The distribution would not conform to the normal curve for researchers when past influence, preferential attachment, and environmental influences are taken into consideration. At the moment, the large majority of reviewed studies, using inferential statistics of mean and standard deviations, does not account for such dynamic influences upon the variables. Is there an alternative that could complement this limitation?

\subsubsection{Linearity in a Predominantly Closed System}

The dominant analytical tools adopted in educational leadership research involve relational and associational analyses of the effects of leadership actions and interventions in schools. The focus is on identifying variables, factors, and their associations in providing explanations of successful practices. The central concept of relations is based on the assumption of linearity. Linearity means two things: Proportionality between cause and effect, and superposition (Nicolis, Prigogine, \& Nocolis, 1989). According to this principle, complex problems can be broken down into simpler problems, which can be solved individually. That is, the effects of interventions can be reconstructed by summing up the effects of the single causes acting on the single variable. This, then, allows establishing causality efficiently.

However, this assumption forces researchers to accept that systems are in equilibrium. The first implication is that the number of possible outcomes in a system is limited (because of the limited number of variables within a closed system). The second implication is that moments of instability, such as through an intervention from the school leader, are brief, whereas the duration of the stability of the final outcome is long. In that case, one can measure effects or establish relations, and accept its data value as a true indication of the cause of intervention. For this to be true, however, the many variables in the school (as a closed system) must be assumed to be independent. Other possibilities to this assumption are to have 
interdependence, mutual causality, and the occurrence of possible external influences in the larger system (e.g. political or economic change).

The goal of school leadership is to improve student achievement. Student achievement is demonstrable, even though there are considerable differences of opinion about how to define improvement in learning or achievement (LarsenFreeman, 1997). This is because much research assumes that the classroom is a closed system with defined boundaries, variables, and predictable outcomes. This mechanistic linear view neglects students as active constructors of meaning with diverse views, needs, and goals (Doll Jr, 1989). It is debatable to draw the association directly that teachers' pedagogy results in learning. Luo, Hogan, Yeung, Sheng, and Aye (2014) found that Singapore students attributed their academic success mainly to internal regulations (effort, interest, and study skills), followed by teachers' help, teachers' ability, parents' help, and tuition classes. While the study appears to support linearity and attribute students' academic success to identified variables, there is still much less certainty about other aspects, such as the interaction effects among the variables. The use of generalized linearity cannot account for the interactions among students - how they motivate each other, how they compete, and how they derive the drive to perform. Researchers studying student achievement tend to seek to reduce and consolidate variables in order to discover order while denying irregularity.

Due to its simplicity, linearity became almost universally adopted as the true assumption along with its corresponding measures in educational leadership research. School improvement, student learning, staff capacity, and efficacy are much more complex than directly assigned proportionality between factors and outcomes, and identifying superposition. Cziko (1989, p. 17) asserted that "complex human behaviour of the type that interests educational researchers is by its nature unpredictable if not indeterminate, a view that raises serious questions about the validity of quantitative, experimental, positivist approach to educational research." In general, school improvement ought to include a notion of and methodology for describing non-linear cognitive systems or processes and to accept that research questions cannot be simplified to find answers from regression models alone, particularly research questions that involve non-specified outcome variables. For instance, school success, in addition to internal variables and factors, simultaneously includes influence by changes in government policies and conflicting demands of multiple stakeholders (e.g. economic and society-related stakeholders). Relying only on the linearity within a closed system will limit any understanding of such interdependencies and mutual influences. Therefore, a holistic and more complete understanding of social phenomena, such as why some school systems in some countries are more successful than others, requires an appreciation and application of research methods that include the elements of open and closed systems. The alternative to linearity - non-linearity, emergence, and self-organization - as an alternate view of reality shall be discussed in the fourth part of this chapter. 


\subsubsection{Explanatory, Explorative, and Descriptive Research}

One of the research aims in social science is the understanding of subjectively meaningful experiences. The school of thought that stresses the importance of interpretation and observation in understanding the social situation in schools is also known as 'interpretivism.' This is an integral part of qualitative research methodologies and analytical tools adopted in educational leadership research. The interrelatedness of different aspects of staff members' work (teaching, professional development), interactions with students (learning, guidance, etc.), cultural factors, and others, form a very important focus of qualitative research. Qualitative research practice has reflected this in the use of explanatory, explorative, and descriptive methods, which attempt to provide a holistic understanding of research participants' views and actions in the context of their lives overall.

Ritchie, Lewis, Nicholls, and Ormston (2013) provide clear explanations for the following research practices: Exploratory research is undertaken to explore an issue or a topic. It is particularly useful in helping to identify a problem, clarify the nature of a problem or define the issues involved. It can be used to develop propositions and hypotheses for further research, to look for new insights or to reach a greater understanding of an issue. For example, one might conduct exploratory research to understand how staff members react to new curriculum plans or ideas for developing holistic achievement, or what teachers mean when they talk about 'constructivism,' or to help define what is meant by the term 'white space.'

A significant number of qualitative studies reviewed in this paper are about description as well as exploration - finding the answers to the Who? What? Where? When? How? and How many? questions. While exploratory research can provide description, the purpose of descriptive research is to answer more clearly defined research questions. Descriptive research aims to provide a perspective for social phenomena or sets of experiences.

Explanatory research addresses the Why questions: Why do staff members value empowerment? Why do some staff members perceive the school climate negatively and others do not? Why do some students have a high self-motivation and others do not? What might explain this? Explanatory, in particular qualitative research assists in answering these types of questions, which allows ruling out rival explanations, guidance to come to valid conclusions, and developing causal explanations.

An obvious limitation of explanatory, explorative, and descriptive educational leadership research is that this is done after an intervention; another limitation constitutes the mere focus on outcomes. If research tapped into this process before interventions were implemented, then two reasonable questions would be:

- Will an intended school vision or policy have the desired positive reception among staff members?

- How can one predict the kind of reception or perception staff members might have? 
The answers would be useful for school leaders in order to initiate intervention measures before serious damage occurs. It would be most useful to be able to extrapolate those answers to the larger system, where policy makers are interested in predicting likely outcomes of the policy prior to its implementation. An example of this kind of research is the development of models known as simulations. Computer simulation is known as the third disciplined scientific methodology. This concept will be discussed in the latter section on alternative methodologies.

A summary of the limitations of current methodologies in educational leadership is concisely captured by Leithwood and Jantzi (1999, p. 471): "Finally, even the most sophisticated quantitative designs used in current leadership effects research treat leadership as exogenous variable influencing students, sometimes directly, but mostly indirectly, through school conditions, moderated by student background characteristics. The goal of such research usually is to validate a specific form of leadership by demonstrating significant effects on the school organization and on students. The logic of such designs assumes that influence flows in one direction from the leader to the student, however tortuous the path might be. But the present study hints at a far more complex set of interactions between leadership, school conditions, and family educational culture in the production of student outcomes."

\subsection{The Current Landscape of Schooling}

\subsubsection{Complexity of Schools: Systems and Structures}

Murphy (2015) examined the evolution of education from the industrial era in the USA (1890-1920) to the post-industrial era of the 1980s. He concluded that postindustrial school organizations have fundamentally shifted in roles, relationships, and responsibilities. The shift is seen in the blurring of distinctions between administrators and teachers; general (expanded) roles instead of specialization, where specialization is no longer held in high regard, as compared to the industrial era, with greater flexibility and adaptability. In terms of structures, the traditional hierarchical organizational structures are giving way to structures that are flatter.

This shift in roles, relationships, and responsibilities has (also) contributed to the increasing complexity of schools. The direct and indirect involvement between and among a growing circle of stakeholders within the school and between government, employers, and communities clearly support the view that schooling is no longer seen as a closed system. It is both a closed and open system (Darling-Hammond, 2010; Hargreaves \& Shirley, 2009; Leithwood \& Day, 2007). Leithwood and Day (2007) state that "Schools are dynamic organizations, and change in ways that cannot be predicted," as they reviewed leadership studies from eight different countries. Open systems are "a system in exchange of a matter with its environment" (Von Bertalanffy, 1968, p. 141). Schools as an open system are therefore seen as part of a much larger network rather than an independent, self-standing entity. 
Thus, to understand the processes still existing within the schools, it is critical to study the interrelations between those entities and their connections to the whole system. The interrelationships among stakeholders are non-linear and discontinuous, so even small changes in variables can have a significant impact on the whole system. This notion of small change leading to global change is reflected in the example of the current 'world-class education system' movement. From countries as diverse as the United Arab Emirates, Brazil, Hong Kong, Singapore, Vietnam, Australia, and the United States of America, a common theme found in education reform documents is the term "world-class education." This term has become widely associated with comparative results on international tests, such as Trends in International Mathematics and Science Study (TIMSS), and the Programme for International Student Assessment (PISA), which purports to measure certain aspects of educational quality. Indeed, the term is frequently used by countries that have attained high scores in these international tests as a strong indicator of being worldclass. This seemingly small aspect of change (i.e. the comparing of achievements in Mathematics and Science) has impacted developing and developed nations in reforming their education system and in calling their ongoing education reforms as moving towards a 'world-class education system.'

Thus, interrelationships in an open system require sophisticated analyses of their systemic nature. A reductionist and linear sequential relationship investigation would not be sufficient in order to bring about further change. To remain of value with the current trends, educational leadership researchers, who adopt complexity methodology, would help practitioners shaping the future by creating an environment of valid knowledge.

\subsubsection{Shared and Distributed Leadership}

The idea of distributed leadership connects well with the trend towards greater decentralization (since the 1980s) and school autonomy through which school leaders are expected to play a greater role in leadership beyond the school borders and requires them to make budgetary decisions, foster professional capacity development, and play a role in the design of school buildings, and many more aspects (Glatter \& Kydd, 2003; Lee, Hallinger, \& Walker, 2012; Nguyen, Ng, \& Yap, 2017; Spillane, Halverson, \& Diamond, 2001).

A core function of leadership - distributed leadership included - is decisionmaking. The most popular discussion of decision-making of the twenty-first century emanates from the concept of decentralization. Decentralization includes delegating responsibilities, practice of distributed leadership, and practice of distributed or shared instructional leadership (Lee et al., 2012; Nguyen et al., 2017; Spillane et al., 2001).

Glatter and Kydd (2003) identified two models of decentralization, which have important implications for school leaders, namely local empowerment and school empowerment. In local empowerment, the transfer of responsibilities takes place 
from the state to the districts, including schools with reciprocal rights and obligations. Therefore, school leaders are expected to play a greater role in leadership beyond school borders. Within the context of school empowerment or autonomy, decision-making by the school has been a consistent movement since the 1980s. The increase in autonomy required the school leaders to make budgetary changes, promote professional capacity development, rethink the design of school buildings, and consider many more aspects.

How might national and state policy frameworks (including curriculum and assessment, school quality and improvement) successfully engage and interact with key activities and characteristics of the school (including learning focus, structure, culture, and decision-making capacity)? What considerations must be taken when formulating policies of curriculum and implementation of policies within the classroom (class size, teaching approaches, and learning resources)? How does one optimize the capacity and work of school leaders to influence and promote effective learning? How might one be informed of the processes of influence beyond relying on interpretive and explanatory qualitative studies? Indeed, any attempt to design and carry out a comprehensive analysis of the ways in which leaders influence and promote successful outcomes through their decision-making will require specific methods and procedures beyond the traditional research methods (Leithwood \& Levin, 2005). In particular, distributed leadership research stands to gain the most if relevant research methodologies were adopted that could be informative of the workings/actions of school leadership.

\subsection{What Are the Alternatives to Current Social Science Methodologies for Educational Leadership?}

As stated earlier, it is important to ensure that any alternative research methodologies proposed must adhere to the characteristic of disciplined inquiry. To further expand on this characteristic, Cronbach and Suppes stated that "Disciplined inquiry does not necessarily follow well-established, formal procedures. Some of the most excellent inquiry is free-ranging and speculative [...] trying what might seem to be a bizarre combination of ideas and procedures..." (Cronbach \& Suppes, 1969, p. 16).

Drawing from the statement by Cronbach and Suppes, there are two other important points about disciplined inquiry that must be addressed here. Disciplined inquiry is not solely focussed on establishing facts. The methods of observation and inquiry are critical in defining which selection of facts of a phenomenon are found. Establishing facts can be done through a selection of observations and/or data collection methods. This point is not meant to raise the philosophical argument of positivism and post-positivism although it may be implied. Rather, from a pragmatic perspective, and to adhere to the characteristic of disciplined inquiry, one should be open to different types of observations and data collection methodologies, and thus different types of facts, as long as the definition of disciplined inquiry is adhered to. 
To further support this view, it must be understood that the field of educational leadership is not a discipline by itself. As in any field of study, one should not be limited to a single discipline to dictate and direct the focus and forms of studies. Instead, procedures and perspectives of different disciplines, such as biology, chemistry, economics, geography, politics, anthropology, sociology, and others might bear on the research questions that can be investigated.

\subsubsection{Brief Introduction to Complexity Science from an Educational Leadership Perspective}

Complexity science appeared in the twentieth century in response to criticism of the inadequacy of the reductionist analytical thinking model in helping to understand systems and the intricacies of organizations. Complexity science does not refer to a single discipline; like in social science, a family of disciplines (psychology, sociology, economics, etc.) adopt methodologies to study society-related phenomena. Complexity science includes the disciplines of non-linear dynamical systems, networks, synergetics, and complex adaptive systems, and others.

The cornerstone concept of complexity science is the complex system. Complex systems have distinctive characteristics of self-organization, adaptive ability, emergent properties, non-linear interactions, and dynamic and network-like structures (Bar-Yam, 2003; Capra, 1996; Cilliers, 2001). By looking at the complex system of an organization, leadership should, consequently, be viewed in a different light. A complex system is a 'functional whole,' consisting of interdependent and variable parts. In other words, unlike a conventional system (e.g. an aircraft), the parts need not have fixed relationships, fixed behaviours, or fixed quantities. Thus, their individual functions may also be undefined in traditional terms. Despite the apparent tenuousness of this concept, these systems form the majority of our world, and include living organisms and social systems, along with many inorganic natural systems (e.g. rivers). The following is a brief introduction of key concepts of complexity science. These concepts are also the methodological assumptions for complexity science.

\subsubsection{Emergence}

Emergence is a key concept in understanding how different levels are linked in a system. In the case of leadership, it is about how influence happens at the individual, structural, and system levels. These different levels exist simultaneously, and one is not necessarily more important than the other, rather they are recognized as coexisting and linked. 
Each level has different patterns and can be subjected to different kinds of theorization. Patterns at 'higher' levels can emerge in ways that are hard to predict at the 'lower' levels. The challenge (long-acknowledged in leadership research) is to understand how different levels interact and affect school outcome or school improvement. This question of the nature of 'emergence' has been framed in a variety of ways, including those of "macro-micro linkage," "individual and society," the "problem of order," and "structure, action and structuration" (Giddens, 1984). In this paper, Giddens' explanation of emergence as the relationship between the different levels through the "structure and agency" is adopted.

Giddens stated that the term "structure" referred generally to "rules and resources." These properties make it possible for social practices to exist across time and space and that lends them 'systemic' form (Giddens, 1984, p. 17). Giddens referred to agents as groups or individuals who draw upon these structures to perform social actions through embedded memory, called memory traces. Memory traces are, thus, the vehicle by which social actions are carried out. Structure is also, however, the result of these social practices.

\subsubsection{Non-linearity}

Non-linearity refers to leadership effects or outcomes that are more complicated than being assigned to a single source or single chain of events. Influence and outcome are considered linear if one can attribute cause and effect. Non-linearity in leadership, however, means that the outcome is not proportional to the input and that the outcome does not conform to the principle of additivity, i.e. it may involve synergistic reactions, in which the whole is not equal to the sum of its parts.

One way to understand non-linearity is about how small events lead to large scale changes in systems. Within the natural sciences, the example often cited (or imagined) is that of a small disturbance in the atmosphere in one location, perhaps as small as the flapping of a butterfly's wings, tipping the balance of other systems, leading ultimately to a storm on the other side of the globe (Capra, 1997).

\subsubsection{Self-Organization}

Self-organization happens naturally as a result of non-linear interactions among staff members in the school (Fontana \& Ballati, 1999). As the word describes, there is no central authority guiding and imposing the interactions. Staff members adapt to changing goals and situations by adopting communication patterns that are not centrally controlled by an authority. In the process of working towards a goal (e.g. solving a leadership problem), self-organizing staff members tend to exhibit creativity and novelty as they have to quickly adapt and to find ways and means to solve the problem and achieve the goal. 
This particular phenomenon is best observed in distributed leadership ( $\mathrm{Ng} \& \mathrm{Ho}$, 2012; Yuen, Chen, \& Ng, 2015). As a result of interactions among members, the emergence of new patterns in conversation happens. This is an important aspect of self-organization. When there are no new patterns in conversations, there are no new ideas and no novel ways to solve problems. It must be noted that new patterns of conversation depend upon the responsiveness of its members towards each other and their awareness of each other's ideas and responses. As a result of the behaviour of interacting members, learning and adaptation, i.e. novel ways of solving problems emerge.

As stated earlier, complexity science is interdisciplinary and as such, there are multiple methods and ways to study complexity phenomena. It is nearly impossible to delve into these methodologies in a meaningful manner within the scope of one paper.

The intention with this paper is to propose alternative social science methodologies and analytical tools to perform educational leadership research. The following section will highlight one of the methods used in complexity science research that provides an alternative to the limitations identified in current research methodologies in educational leadership research.

\subsection{Social Network Analysis as an Alternative to Normal Distribution and Linearity}

Social Network Analysis (Scott, 2011; Wasserman \& Faust, 1994) focuses on relational structures that characterize a network of people. These relational structures are represented by graphs of individuals and their social relations, and indices of structure, which analyze the network of social relationships on the basis of characteristics such as neighbourhood, density, centrality, cohesion, and others. The Social Network Analysis-method has been used to investigate educational issues, such as teacher professional networks (Baker-Doyle \& Yoon, 2011; Penuel, Riel, Krause, \& Frank, 2009), the spread of educational innovations (Frank, Zhao, \& Borman, 2004), and peer influences on youth behaviour (Ennett et al., 2006). Table 7.4 provides examples of the types of data collected, and the analytical methods and analytical tools used in social network analysis.

In network analysis, indicators of centrality identify the most important vertices within a graph. Two separate measures of degree centrality, namely in-degree and out-degree, are used. In-degree is a count of the number of ties directed to the node (agent/individual) and out-degree is the number of ties that the node (agent/individual) directs to others. When ties are associated to positive aspects, such as friendship or collaboration, in-degree is often interpreted as a form of popularity and out-degree as a form of gregariousness.

For example, the study of Bird and colleagues (Bird, Gourley, Devanbu, Gertz, \& Swaminathan, 2006) introduces social network analysis and the evidence of longtailed distribution, which is a distinctive digression from the traditional social 
Table 7.4 Social network data

\begin{tabular}{|c|c|}
\hline Data: & Types and methods: \\
\hline \multirow[t]{8}{*}{$\begin{array}{l}\text { Types of data collected for Social } \\
\text { Network Analysis }\end{array}$} & $\begin{array}{l}\text { Social bonds (interpersonal ties, friendship, family } \\
\text { networks) }\end{array}$ \\
\hline & $\begin{array}{l}\text { Organizational links (connection between residents and } \\
\text { community organizations) }\end{array}$ \\
\hline & $\begin{array}{l}\text { Media connection (specific media that residents and } \\
\text { organizations rely upon for news) }\end{array}$ \\
\hline & Identify boundaries \\
\hline & Clarify and design questions \\
\hline & "Actually existing social relations" \\
\hline & "Perceived relations" \\
\hline & $\begin{array}{l}\text { Dynamism: "Episodic" relations or "typical"/“long } \\
\text { term" ties }\end{array}$ \\
\hline \multirow{6}{*}{$\begin{array}{l}\text { Methods used to collect data for } \\
\text { Social Network Analysis }\end{array}$} & Surveys \\
\hline & Interviews \\
\hline & Facebook, LinkedIn \\
\hline & Data mining (internet, emails) \\
\hline & Archival data \\
\hline & Observations \\
\hline \multirow{8}{*}{$\begin{array}{l}\text { Analytical tools for Social Network } \\
\text { Analysis }\end{array}$} & Netlogo \\
\hline & Netdraw \\
\hline & UCINET \\
\hline & NodeXL \\
\hline & Gephi \\
\hline & PAJEK \\
\hline & SPAN \\
\hline & STATNET \\
\hline
\end{tabular}

science study and the normal distribution associated with it. The evidence from social network measures in this research suggests that "developers who actually commit changes, play much more significant roles in the e-mail community than non-developers" (Bird et al., 2006, p. 142). What this conclusion alludes to is that knowledgeable and active developers who demonstrate their ability by actively responding and making changes (out-degree) based on feedback are more often contacted by e-mail queries from other users.

\subsubsection{How Does Social Network Analysis Contribute to Educational Leadership Research?}

The usefulness of social network analysis is reflected in a study (co-conducted by the author) on instructional leadership practices in primary schools in a centralized system where hierarchical structures are in place (Nguyen et al., 2017). It is noteworthy that the hierarchical structure's inherent reliance on a 'supreme leader' is 
greatly mitigated by the emergence of heterarchical elements. In brief, hierarchical structures, on the one hand, are vertical top-down control and reporting structures. Heterarchical structures, on the other hand, are horizontal. The findings revealed that at the teachers' and other key personnel's horizontal levels of hierarchy, spontaneous interactions and collaborations take place within a group and amongst groups of teachers. Through these horizontal professional interactions, individuals exert reciprocal influences on one another, with the minimal effects of authority power. In this structure, distributed instructional leadership appears to be deliberately practiced. Key personnel and teachers work in collaborative teams and are supported by organizational structures, initiated by the principals. This is where various instructional improvement programmes and strategies are initiated, implemented, and led by staff members. This would be highly impossible, if the principal practices were heavily based on hierarchical instructional leadership.

This study implies that decision-making on instructional improvement programmes is rigorously and actively practiced by teachers at the heterarchical level. Decision-making involves getting support for resources and approval from authorities over the teachers. In an organizational hierarchical structure, it would be the authority immediately above the teachers - the Head of Department, followed by the Vice Principal, and finally the Principal. Typically, such a reporting and resource seeking structure would be ineffective in creating instructional improvement programmes. If one was to redo the study and adopt social network analysis measures, how would the findings be presented? The figures below are hypothetically generated to provide a possible way to interpret hierarchical and heterarchical structures: Fig. 7.1 shows a social network representation, which provides an alternative way to represent hierarchy. The central (purple dot) represents the Principal, while the connected red dots to the Principal are the Head of Departments. The Head of Departments then oversees Subject Heads and finally teachers. Implying from our

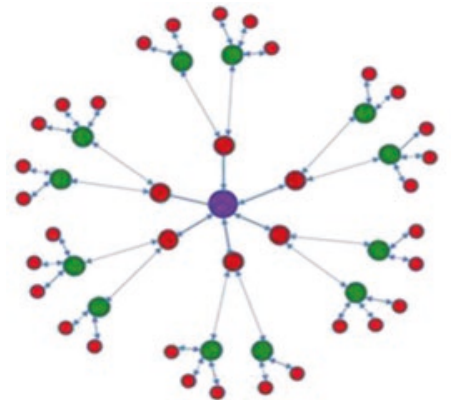

A: Expected

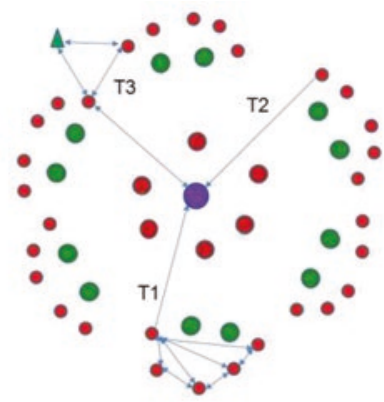

B: Actual

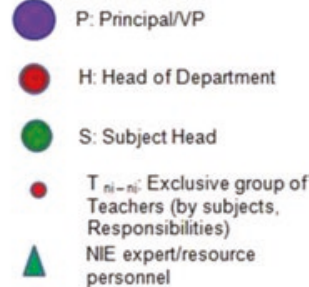

Legend

Fig. 7.1 Expected and actual reporting and decision-making pathways in managing teaching and learning

Note: In B, T1 = perceived authority for immediate action (e.g. allocation of resources, ability to act); $\mathrm{T} 2=$ perceived trust; $\mathrm{T} 3=$ pilot curriculum project 
study, where heterarchical elements are exhibited, social network representation will most plausibly provide the means to represent the elements in Fig. 7.1.

What is immediately evident, is that the representation provides a more realistic way to look at social interactions involving decision-making. The connected dots among teachers could reveal who they interact most with. In addition, what would be most revealing is the emergence of how teachers in hybrid hierarchical and heterarchical structures make decisions. Specifically, the emergence of by-passing the constraints of a typical top-down hierarchical structure by directly getting support from centrality - the principal, who controls and provides resources and who also approves final decisions.

In summary, the discussion on one of the complexity science methodologies/ social network analysis presents opportunities to reframe educational leadership research. It is now possible to ask research questions that are not bound by the constraints of current social science methodologies. Here are a number of questions using Social Network Analysis alone:

- What is the local (indigenous) knowledge base of instructional leadership and how does it emerge?

- How do different level leaders (Ministry of Education, Superintendents, Principals, etc.) shape the perception of curriculum policies in schools? (And for specific local understanding - who are the influential personnel impacting curriculum and policy implementation?)

- Examination of ties among school departments that affect school improvement: What are the implications for long-term strategy processes for school improvement in light of the complex and adaptive nature of departments?

- What does engagement in decision-making look like?

- How do aspects of relations within the network: structural (pattern of interaction, face-to-face interaction), affective (benevolence and trust), and cognitive (mutual knowledge about each other's skills and knowledge, and shared systems of meaning) affect professional development and learning?

- Will an intended school vision/policy enjoy the desired positive reception among staff members?

\subsection{Conclusion}

This chapter contains the review that social science methodologies and analytical tools have been consistently and almost universally adopted in educational leadership research for the last three decades. This paper also highlights a number of limitations of current social science methodologies. The alternative complexity science research methodologies proposed are not merely alternative or novel ways of examining the problems or issues encountered. What is more valuable is that these 
alternative methodologies bring with them their contrasting disciplinary roots and their corresponding (new) questions. The interest in the effects of educational leadership on school improvement can now be investigated by asking different research questions. One could, indeed, go deeper, wide-angle or zoom-in, and even make predictions by revisiting the basic question of "What do we wish to know about school improvement that we do not yet know enough about?"

By being open to alternative methodologies, one has nothing to lose but everything to gain in the scholastic pursuit of knowledge in the field of educational leadership and management. Researchers must avoid being educational leadership researchers who see the world merely from the perspectives that they have lived in; they should also avoid accepting these perspectives as the only perspectives without questions. The choice of research method or combination of methods affects the type of research questions asked (although, in practice, the questions are also often shaped by the researchers' training and area of expertise). Ideally, one should not be constrained by methods before asking research questions. Research questions are the primary drivers of the quest for knowledge. This is the basis from which the most relevant methodologies are found that can answer research questions and provide researchers with the findings that can contribute to theory formation, knowledge building, and translation into practice. The author, therefore, proposes the following implications for practice and for research:

- Introduce complexity science (and also other disciplines) as additional graduate research courses. One can still tap on the transmission-form of knowledge transfer and supervisor-supervisee platform.

- Partner with established experts in the discipline of complexity science to leverage and speed up transfer of learning and research skills among educational leadership professors.

- Engage in epistemological and ontological discussions (including generalizability of findings) on complexity theory - to deepen our understanding of the advantages and limitations of complexity science disciplined inquiries.

- Expand educational leadership journals to accept findings and research that do not necessarily conform to social science methodologies alone.

Finally, reframing educational leadership research is an imperative in the light of diminishing researchable aspects due to the limitations of current methodologies. I, the author, want to reiterate that I do not advocate replacing existing social science methodologies. I acknowledge that social methodologies are still essential and vital. The full spectrum of social science research methodologies is needed to continue contributing to theory development in educational leadership and management. However, one also needs alternatives and complementary approaches to social science, such as complexity science methodologies for both theory development and theory building. The important thing to remember is that the questions come first and the methods follow. 


\section{References}

Andriani, P., \& McKelvey, B. (2007). Beyond Gaussian averages: Redirecting international business and management research toward extreme events and power laws. Journal of International Business Studies, 38(7), 1212-1230.

Baker-Doyle, K. J., \& Yoon, S. A. (2011). In search of practitioner-based social capital: A social network analysis tool for understanding and facilitating teacher collaboration in a US-Based STEM professional Development program. Professional Development in Education, 37(1), 75-93.

Bar-Yam, Y. (2003). Unifying principles in complex systems in converging technology (NBIC) for improving human performance. In M. C. Roco \& W. S. Bainbridge (Eds.), Converging technologies for improving human performance: Nanotechnology, biotechnology, information technology and cognitive science (pp. 380-409). Dordrecht, The Netherlands: Kluwer Academic Publishers.

Bass, B. M. (1997). Does the transactional-transformational leadership paradigm transcend organizational and national boundaries? American Psychologist, 52(2), 130.

Bennett, N., Wise, C., Woods, P., \& Harvey, J. A. (2003). Distributed leadership. Available at: www.ncsl.org.uk/media/3C4/A2/distributed-leadership-literature-review.pdf. Accessed 28 July 2006.

Bhattacherjee, A. (2012). Social science research: Principles, methods, and practices. Textbook Collections, 3rd Global Text Project. Retrieved from http://scholarcommons.usf.edu/ oa_textbooks/3/

Bird, C., Gourley, A., Devanbu, P., Gertz, M., \& Swaminathan, A. (2006, May). Mining email social networks. In Proceedings of the 2006 international workshop on mining software repositories (pp. 137-143). New York, NY: ACM.

Boyan, N. J. (1981). Follow the leader: Commentary on research in educational administration. Educational Researcher, 10(2), 6-13. 21.

Capra, F. (1996). The web of life: A new scientific understanding of living systems (1st ed.). New York, NY: Anchor.

Capra, F. (1997). The name above the title: An autobiography. New York, NY: Da Capo Press.

Cilliers, P. (2001). Boundaries, hierarchies and networks in complex systems. International Journal of Innovation Management, 5(2), 135-147.

Clauset, A., Shalizi, C. R., \& Newman, M. E. (2009). Power-law distributions in empirical data. SIAM Review, 51(4), 661-703.

Cronbach, L. J., \& Suppes, P. (1969). Research for tomorrow's schools: Disciplined inquiry for education. New York, NY: Macmillan.

Cziko, G. (1989). Unpredictability and indeterminism in human behavior: Arguments and implication for educational research. Educational Researcher, 18, 17-25.

Darling-Hammond, L. (2010). Teacher education and the American future. Journal of Teacher Education, 61(1-2), 35-47.

Day, C., Sammons, P., Leithwood, K., Hopkins, D., Harris, A., Gu, Q., \& Brown, E. (2010). Ten strong claims about successful school leadership. Nottingham, UK: The National College for School Leadership.

Dimmock, C. (2000). Globalisation and societal culture: Redefining schooling and school leadership in the twenty-first century. Compare, 30(3), 1-6.

Dimmock, C., \& Walker, A. (2005). Educational leadership: Culture and diversity. London, UK: Sage.

Doll, W. E., Jr. (1989). Foundations for a post-modern curriculum. Journal of Curriculum Studies, 21(3), 243-253.

Ennett, S. T., Bauman, K. E., Hussong, A., Faris, R., Foshee, V. A., Cai, L., \& DuRant, R. H. (2006). The peer context of adolescent substance use: Findings from social network analysis. Journal of Research on Adolescence, 16(2), 159-186. 
Fontana, W., \& Ballati, S. (1999). Complexity. Complexity, 4, 14-16. https://doi.org/10.1002/(SIC I) 1099-0526(199901/02)4:3<14:AID-CPLX3>3.0.CO;2-O

Frank, K. A., Zhao, Y., \& Borman, K. (2004). Social capital and the diffusion of innovations within organizations: The case of computer technology in schools. Sociology of Education, 77(2), $148-171$.

Giddens, A. (1984). The constitution of society: Outline of the theory of structuration. Oakland, CA: University of California Press.

Glatter, R., \& Kydd, L. (2003). Best practice in educational leadership and management: Can we identify it and learn from it? Educational Management \& Administration, 31(3), 231-243.

Goldring, E., \& Greenfield, W. (2002). Understanding the evolving concept of leadership to education: Roles, expectations, and dilemmas. Yearbook of the National Society for the Study of Education, 101(1), 1-19.

Griffiths, D. E. (1959). Administrative theory. New York, NY: Appleton-Century-Crofts.

Griffiths, D. E. (1979). Intellectual turmoil in educational administration. Educational Administration Quarterly, 15(3), 43-65.

Gronn, P. (2002). Distributed leadership as a unit of analysis. Leadership Quarterly, 13, 423-451.

Gronn, P. (2009). From distributed to hybrid leadership practice. In Distributed leadership (pp. 197-217). Springer, Dordrecht.

Hallinger, P. (2003). Leading educational change: Reflections on the practice of instructional and transformational leadership. Cambridge Journal of Education, 33(3), 329-351.

Hallinger, P. (2011). Leadership for learning: Lessons from 40 years of empirical research. Journal of Educational Administration, 49(2), 125-142.

Hallinger, P. (2013). A conceptual framework for reviews of research in educational leadership and management. Journal of Educational Administration, 51(2), 126-149.

Hallinger, P., \& Heck, R. H. (1996). Reassessing the principal's role in school effectiveness: A review of empirical research, 1980-1995. Educational Administration Quarterly, 32(1), 5-44.

Hallinger, P., \& Murphy, J. (1985). Assessing the instructional management behavior of principals. The Elementary School Journal, 86(2), 217-247.

Hallinger, P., \& Murphy, J. F. (1986). The social context of effective schools. American Journal of Education, 328-355.

Hallinger, P., Walker, A. D., \& Bajunid, I. A. (2005). Educational leadership in East Asia: Implications for education in a global society. UCEA Review, 1, 1-4.

Hargreaves, A. P., \& Shirley, D. L. (Eds.). (2009). The fourth way: The inspiring future for educational change. Thousand Oaks, CA: Corwin Press.

Harris, A. (2005). OP-ED. Journal of Curriculum Studies, 37(3), 255-265.

Howell, J. M., \& Avolio, B. J. (1993). Transformational leadership, transactional leadership, focus of control, and support for innovation: Key predictors of consolidated business-unit performance. Journal of Applied Psychology, 78(6), 891.

Larsen-Freeman, D. (1997). Chaos/complexity science and second language acquisition. Applied Linguistics, 18(2), 141-165.

Lee, M., Hallinger, P., \& Walker, A. (2012). A distributed perspective on instructional leadership in International Baccalaureate (IB) schools. Educational Administration Quarterly, 48(4), 664-698.

Leithwood, K., \& Day, C. (2007). Successful school leadership in times of change. Toronto, ON: Springer.

Leithwood, K., \& Duke, D. (1999). A century's quest to understand school leadership. In J. Murphy \& K. Louis (Eds.), Handbook of research on educational administration (pp. 45-72). San Francisco, CA: Jossey-Bass.

Leithwood, K., \& Jantzi, D. (1999). Transformational school leadership effects: A replication. School Effectiveness and School Improvement, 10(4), 451-479.

Leithwood, K., \& Jantzi, D. (2000). The effects of transformational leadership on organizational conditions and student engagement with school. Journal of Educational Administration, 38(2), $112-129$. 
Leithwood, K., \& Levin, B. (2005). Understanding leadership effects on pupil learning. Toronto, UK: UK Department of Skills and Education.

Leithwood, K., Tomlinson, D., \& Genge, M. (1996). Transformational school leadership. In K. Leithwood, J. Chapman, D. Corson, P. Hallinger, \& A. Hart (Eds.), International handbook of educational leadership and administration (pp. 785-840). Dordrecht, The Netherlands: Springer.

Luo, W., Hogan, D. J., Yeung, A. S., Sheng, Y. Z., \& Aye, K. M. (2014). Attributional beliefs of Singapore students: Relations to self-construal, competence and achievement goals. Educational Psychology, 34(2), 154-170.

MacBeath, J., \& Cheng, Y. C. (2008). Leadership for learning. International perspective (pp. 17-40). Rotterdam, The Netherlands: Sense Publishers.

Meyer, M. J., \& Macmillan, R. B. (2001). The principal's role in transition: Instructional leadership ain't what it used to be. International Electronic Journal for Leadership in Learning, 5(13), 1-14.

Micceri, T. (1989). The unicorn, the normal curve, and other improbable creatures. Psychological Bulletin, 105(1), 156.

Mitzenmacher, M. (2004). A brief history of generative models for power law and lognormal distributions. Internet Mathematics, 1(2), 226-251.

Mulford, B., \& Silins, H. (2003). Leadership for organisational learning and improved student outcomes - What do we know? Cambridge Journal of Education, 33(2), 175-195.

Murphy, J. (2015). Forces shaping schooling and school leadership. Journal of School Leadership, 25(6), 1064.

Ng, F. S. D., \& Ho, J. M. (2012). How leadership for an ICT reform is distributed within a school. International Journal of Educational Management, 26(6), 529-549.

Nguyen, D. H., Ng, D., \& Yap, P. S. (2017). Instructional leadership structure in Singapore: A coexistence of hierarchy and heterarchy. Journal of Educational Administration, 55(2), 147-167.

Nicolis, G., Prigogine, I., \& Nocolis, G. (1989). Exploring complexity. New York, NY: Freeman.

Penuel, W., Riel, M., Krause, A., \& Frank, K. (2009). Analyzing teachers' professional interactions in a school as social capital: A social network approach. The Teachers College Record, $111(1), 124-163$.

Ritchie, J., Lewis, J., Nicholls, C. M., \& Ormston, R. (Eds.). (2013). Qualitative research practice: A guide for social science students and researchers. London, UK: Sage.

Robinson, V. M. (2010). From instructional leadership to leadership capabilities: Empirical findings and methodological challenges. Leadership and Policy in Schools, 9(1), 1-26.

Robinson, V., Lloyd, C., \& Rowe, K. (2008). The impact of leadership on student outcomes: An analysis of the differential effects of leadership types. Educational Administration Quarterly, 44(5), 564-588.

Scott, J. (2011). Social network analysis: Developments, advances, and prospects. Social Network Analysis and Mining, 1(1), 21-26.

Sheppard, B. (1996). Exploring the transformational nature of instructional leadership. Alberta Journal of Educational Research, 42(4), 325-344.

Southworth, G. (2002). Instructional leadership in schools: Reflections and empirical evidence. School Leadership and Management, 22(1), 73-92.

Spillane, J. P. (2005, June). Distributed leadership. The Educational Forum, 69(2), 143-150.

Spillane, J. P., Diamond, J. B., \& Jita, L. (2003). Leading instruction: The distribution of leadership for instruction. Journal of Curriculum Studies, 35(5), 533-543.

Spillane, J. P., Halverson, R., \& Diamond, J. B. (2001). Investigating school leadership practice: A distributed perspective. Educational Researcher, 30(3), 23-28.

Spillane, J. P., Halverson, R., \& Diamond, J. B. (2004). Towards a theory of leadership practice: A distributed perspective. Journal of Curriculum Studies, 36(1), 3-34.

Torres-Carrasquillo, P. A., Singer, E., Kohler, M. A., Greene, R. J., Reynolds, D. A., \& Deller Jr, J. R. (2002, September). Approaches to language identification using Gaussian mixture models 
and shifted Delta Cepstral features. In Proceedings of the international conference on spoken language processing, Denver, CO, pp. 89-92.

Von Bertalanffy, L. (1968). Organismic psychology and systems theory. Worchester, MA: Clark University Press.

Walberg, H. J., Strykowski, B. F., Rovai, E., \& Hung, S. S. (1984). Exceptional performance. Review of Educational Research, 54(1), 87-112.

Walker, A., \& Dimmock, C. (2000). Insights into educational administration: The need for a crosscultural comparative perspective. Asia-Pacific Journal of Education, 20(2), 11-22.

Wasserman, S., \& Faust, K. (1994). Social network analysis: Methods and applications (Vol. 8). New York, NY: Cambridge University Press.

Witziers, B., Bosker, R., \& Kruger, M. (2003). Educational leadership and student achievement: The elusive search for an association. Educational Administration Quarterly, 34(3), 398-425.

Woods, P. A. (2004). Democratic leadership: drawing distinctions with distributed leadership. International journal of Leadership in Education, 7(1), 3-26.

Yuen, J. H. P., Chen, D. T. V., \& Ng, D. (2015). Distributed leadership through the lens of activity theory. Educational Management Administration \& Leadership, 44(5), 814-836.

Open Access This chapter is licensed under the terms of the Creative Commons Attribution 4.0 International License (http://creativecommons.org/licenses/by/4.0/), which permits use, sharing, adaptation, distribution and reproduction in any medium or format, as long as you give appropriate credit to the original author(s) and the source, provide a link to the Creative Commons license and indicate if changes were made.

The images or other third party material in this chapter are included in the chapter's Creative Commons license, unless indicated otherwise in a credit line to the material. If material is not included in the chapter's Creative Commons license and your intended use is not permitted by statutory regulation or exceeds the permitted use, you will need to obtain permission directly from the copyright holder. 